\title{
The effects of Anodonta cygnea biological fluids on biomineralization of chitosan membranes
}

\author{
Anabela Lopes ${ }^{\mathrm{a}}$, Manuel Lopes-Lima ${ }^{\mathrm{a}, \mathrm{b}}$, Iulius Bobos ${ }^{\mathrm{d}}$, Jorge Ferreira ${ }^{\mathrm{e}}$, Sílvia Gomes ${ }^{\mathrm{c}}$, Rui Reis ${ }^{\mathrm{c}}$, \\ João Mano ${ }^{\mathrm{c}}$, Jorge Machado ${ }^{\mathrm{a}, \mathrm{b}, *}$ \\ a Laboratório de Fisiologia Aplicada, Instituto de Ciências Biomédicas Abel Salazar, Largo Prof. Abel Salazar 2, 4099-003 Porto, Portugal \\ b Centro de Investigação Marítima e Ambiental (CIMAR), Rua dos Bragas, 289, 4050-123 Porto, Portugal \\ c 3B's Research Group - Biomaterials, Biodegradables and Biomimetics, Dept. of Polymer Engineering, University of Minho, Campus de Gualter, $4710-057$ Braga, Portugal \\ d Faculdade de Ciências da Universidade do Porto, Rua Campo Alegre 687, 4169-007 Porto, Portugal \\ e Instituto Nacional de Engenharia, Tecnologia e Inovação, I.P., Rua da Amieira 4466-956 S. Mamede de Infesta, Portugal
}

\section{A R T I C L E I N F O}

\section{Article history:}

Received 20 May 2010

Received in revised form 13 July 2010

Accepted 2 August 2010

Available online 10 August 2010

\section{Keywords:}

Chitosan membranes

Biomineralization

$<$ rk-italic $>$ Anodonta cygnea $</$ rk-italic $>$

Biological fluids

\begin{abstract}
A B S T R A C T
The use of chitosan membranes, a low-cost, biocompatible material with promising capabilities in biomedical applications has already been fairly investigated in other fields with good results. Here, the aim was the in vitro mineralization assays accomplished with the chitosan membranes incubated in the control calcium and phosphate solutions on "Ussing" chambers. Biological fluids from Anodonta cygnea were added to the control solutions under different physical-chemical parameters such as $\mathrm{pH}$ synthetic and natural organic compounds. Some organic compounds analyses in the solutions as well as the chitosan membrane SEM-EDS, XRD and FTIR observations were carried out at the end of experimental period. From the experiments it was shown that the chitosan membrane may act as a selective epithelium with preferred ionic movements. Particular mineral deposits, in the chitosan membrane, with hexagonal hydroxiapatite crystals, occurred only at pH 6 with HCL or succinic acid. Biological fluids of $A$. cygnea induced an increase in number and size of hexagonal crystals forming specific rosaceous structures, especially at pH 6 with succinic acid. It seems that proteins, GAGs and lipids can be involved on this process, since there is a significant reduction on its contents after experiments. So, further applied research with these materials can be a promising subject.
\end{abstract}

(C) 2010 Elsevier B.V. All rights reserved.

\section{Introduction}

Chitosan has recently been appointed as a biomaterial with a wide variety of biomedical and industrial applications [1]. It is a linear polyaminosaccharide composed of (1-4)-linked-Dglucosamine and $\mathrm{N}$-acetyl-D-glucosamine, commonly derived at a low-cost from chitin, a waste material from the seafood industry [2]. Important properties like antimicrobial and antitumoral activity, haemostatic and accelerated wound healing, biodegradability, low toxicity and biocompatibility have made chitosan a promising biomaterial of the twenty-first century [3].

Different forms of chitosan-based biomaterials have recently been developed for biomedical purposes, including scaffolds, nanocomposites, tubes, sponges, coatings, microspheres, wound dressings and membranes, which are especially useful for potential

\footnotetext{
* Corresponding author at: Lab. Fisiologia Aplicada, Instituto de Ciências Biomédicas de Abel Salazar, Lg. Prof. Abel Salazar no. 2, 4099-003 Porto, Portugal. Tel.: +35122 2062294; fax: +35122 2062232.

E-mail address: jmachado@icbas.up.pt (J. Machado).
}

applications in bone repair and regeneration. Among the most current topics in this field is the adaptation of in vitro biomineralization experiments to resemble in vivo conditions. In fact, biomineralization is the process by which organisms convert ions in solution into solid minerals. It is also the result of the cellular activity that makes possible the necessary transformations that lead to crystal formation and growth. In order to occur, some requirements are needed: specialized microenvironments where mineral supersaturation may be achieved, a supply of ions and macromolecules, removal of waste products and balanced physical-chemical parameters (e.g., pH, osmolarity). For many reasons the biomineralization phenomenon has been a point of interest for some scientific and technological areas, e.g., in medicine, understanding the deposition of calcium salts in bone cells as part of the growth and repair process is essential in order to develop prosthesis and ostheogenic implants or to avoid pathological calcification of organs and medical devices.

The organic matrix of molluscan shells is thought to be an essential biomineralization mediator [4-6]. The matrix may control crystal nucleation, polymorph selection, crystal orientation and/or crystal growth inhibition [4]. Calcium carbonate/phosphate crystals are well regulated, theoretically through an ionotropic or 
stereochemical mechanism [7-10]. According our studies [9-14], the freshwater mussel Anodonta cygnea is a good model to study biomineralization processes due to have large volume biomineralization compartments with easy access to their organic matrixes. In these animals, biomineralization events occur in two different biomineralization compartments, each with a specific biological fluid, haemolymph and extrapallial fluid, involved in mineral production at the microspherules (mineral concretions) level $[9,10]$ and in the shell calcification respectively. Although the fluids act at different levels of calcification, their organic and inorganic composition is very similar and balanced either by transport across the mantle barrier or by mantle cellular synthesis. Proteins, glycosaminoglycans (GAGs) and hexosamines (chitin) are the major organic constituents known to be important for biomineralization $[9,10]$.

In this view our aim was to gain further knowledge about the basic principles of biomineralization and to evaluate the influence of bivalve biological fluids, which are involved in in vivo biomineralization events.

\section{Experimental}

\subsection{Membrane preparation}

The chitosan membrane was obtained and treated as already described by Mano [15].

\subsection{Biological sample collection}

Freshwater bivalves (A. cygnea) were collected from the clay bottom of Mira lagoon (Aveiro, Portugal). The animals were kept in laboratory in dechlorinated and aerated water for a minimum of 1 day period before the extraction of fluids (haemolymph and extrapallial fluid). For fluids sampling, the animals were considered healthy if they showed active ventilation and powerful valve closing or water ejection upon disturbance. For each experiment, approximately $5 \mathrm{ml}$ of haemolymph and $5 \mathrm{ml}$ of extrapallial fluid were extracted with a needle syringe from two animals. After that, each fluid was centrifuged at $4000 \mathrm{rpm}, 5 \mathrm{~min}$. (Kubota KR20000T, Rotor RA-3R) to remove cellular debris. Subsequently, the supernatant was treated separately in order to be used in each experiment.

\subsection{Kinetic of chitosan membranes}

All further experimental sets, which were replicated four times, were carried out in "Ussing chambers" separated by a chitosan membrane into two compartments: one filled with a phosphate solution and other with a calcium solution (Fig. 1). The chitosan membranes were previously washed with alcohol, air dried and than washed again in distilled water immediately before the insertion between the chambers. In this set of experiences the phosphate chamber was filled with $4 \mathrm{ml}$ of sodium phosphate $(20 \mathrm{mM}, \mathrm{pH}$ $7.5 / \mathrm{HCl}$ ) and the calcium chamber with $4 \mathrm{ml}$ of calcium chloride $(20 \mathrm{mM}, \mathrm{pH} 7.5 / \mathrm{HCl})$. The chambers were closed and kept $6 \mathrm{~h}$ at room temperature. At the end of this period, the solutions of each individual chamber were collected and stored until posterior analysis. These experiments with synthetic solutions were considered as a control situation for further experimental sets. Time and number of replicates, temperature and final collection and storage procedures were the same in all assays to be described.

Calcium and phosphate ions quantifications in solutions were accomplished at time 0 and $6 \mathrm{~h}$ after by atomic absorption spectroscopy and PiBlue ${ }^{\mathrm{TM}}$ Phosphate Assay Kit (Bioassay Systems) respectively.
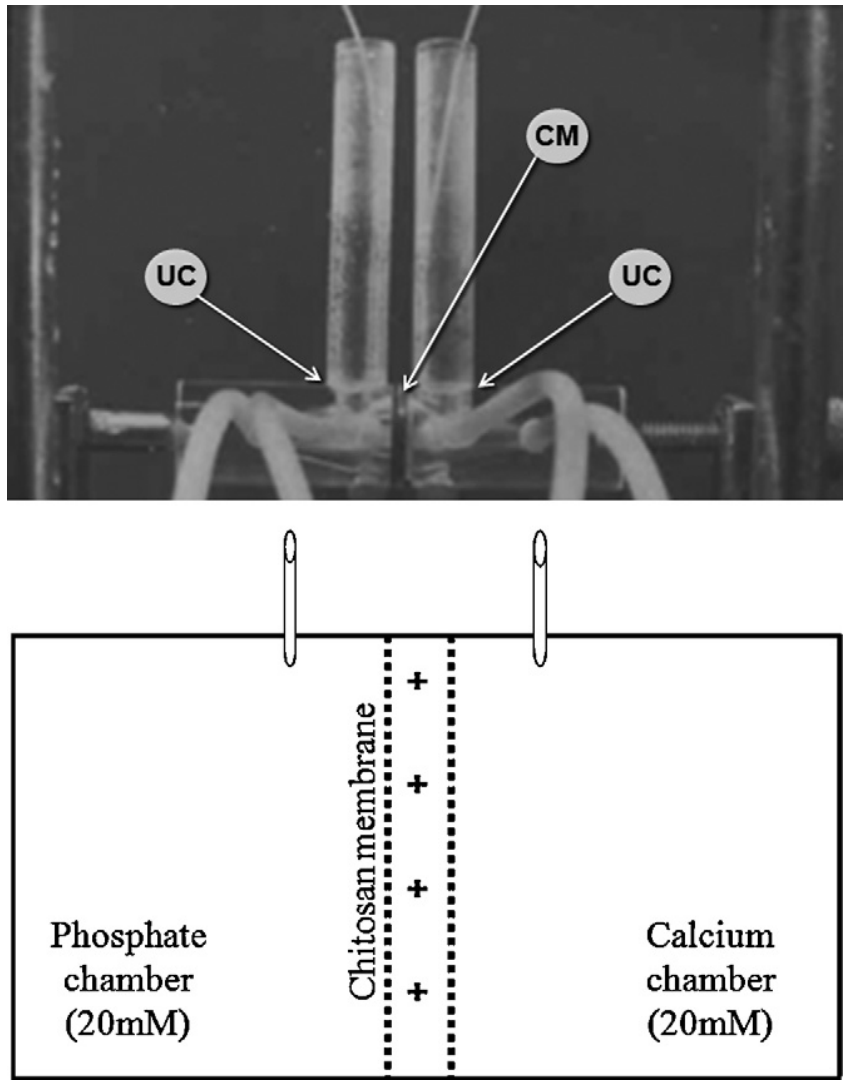

Fig. 1. Photography and schematic view of experimental system with 'Ussing chambers' (UC) separated by a chitosan membrane (CM).

\subsection{Biological fluids effects}

The chitosan membranes were previously treated during $30 \mathrm{~min}$ with haemolymph or extrapallial fluid extracted from A. cygnea mantle. Then, the membranes were inserted between the two chambers according the anterior scheme, already explained (Fig. 1). In the subsequent experimental sets, the addition of haemolymph or extrapallial solutions was only used in the calcium chamber, since the fluid influence on the calcium phosphate precipitation were only evident in the calcium chamber. So, as in the anterior experiments the phosphate chamber was filled with $4 \mathrm{ml}$ of sodium phosphate $(20 \mathrm{mM})$ however the calcium chamber was filled with a biological fluid (haemolymph or extrapallial) with $100 \mu \mathrm{l}$ of calcium chloride to reach a final concentration of $20 \mathrm{mM}$ of calcium. These calculations were made based on previous knowledge on calcium concentration in the biological fluids [16].

The determination of organic compounds concentration on experimental fluids was performed at time 0 and after $6 \mathrm{~h}$. Proteins were quantified according Bradford [17] and total GAGs were quantified according Gold $[18,19]$. For total lipids concentration, a liquid-liquid extraction [20] was carried out followed by quantification using a Total Lipid Kit (Far Diagnostic). The presence of iron ions was detected by atomic absorption spectroscopy (Varian SpectrAA 220FS).

\section{5. $p H$ effect}

Similar experiments, with calcium and phosphate solutions, were also carried out adjusting the $\mathrm{pH}$ solution with $\mathrm{HCl}(1 \mathrm{M})$ at $\mathrm{pH} 6,7$ and with $\mathrm{NaOH}(1 \mathrm{M})$ at 9, for both chambers in order to evaluate the $\mathrm{pH}$ effects. Other experiments at $\mathrm{pH} 6$ with synthetic 
Table 1

Phosphate and calcium variations on the solutions from the first experimental set $(n=12)$.

\begin{tabular}{|c|c|c|c|c|}
\hline & \multicolumn{2}{|l|}{$t=0 \mathrm{~h}$} & \multicolumn{2}{|l|}{$t=6 \mathrm{~h}$} \\
\hline & Phosphate chamber & Calcium chamber & Phosphate chamber & Calcium chamber \\
\hline Phosphate (mmol/L) & 20 & 0 & $16.16 \pm 3.48$ & $0.03 \pm 0.01$ \\
\hline Calcium (mmol/L) & 0 & 20 & $0.058 \pm 0.01$ & $18.75 \pm 0.56$ \\
\hline
\end{tabular}

organic acids, as succinic and citric acids, were carried out with and without haemolymph and extrapallial fluid of $A$. cygnea additions, in order to study the effects of specific organic acids. In these cases, the biological fluids were only added to the calcium chamber while the succinic and citric acids were used in both chambers for $\mathrm{pH}$ balance.

\subsection{Scanning electron microscopy (SEM) imaging}

Membrane pieces from both sides of all experiences were goldcoated (FINE-COAT Ion sputter JFC-1100) and glued to aluminium stubs for SEM observations using JEOL JSM-35C scanning electron microscope (SEM) operated at $10 \mathrm{Kv}$.

\subsection{Fourier transform infrared spectroscopy (FTIR) and X-ray diffraction $(X R D)$}

In all experiments, membrane pieces were analyzed by FTIR. Unlike SEM imaging, FTIR analyses were performed only in the side of membrane that was in contact with the calcium solution (calcium chamber).

For the FTIR analyses, a Bruker Equinox Fourier transform spectrometer was used coupled with a Bruker microscope that collects the IR beam with Cassegrain objectives. Analysis of clay films deposited on a $\mathrm{CaF}_{2}$ disk was carried out by transmission, using a circular diaphragm with a $60 \mathrm{~mm}$ diameter aperture. Each spectrum was processed using the OPUS program $\left({ }^{\circledR}\right.$ Bruker). Spectra of atmospheric $\mathrm{CO}_{2}$ and $\mathrm{H}_{2} \mathrm{O}$ were recorded independently for subtraction purposes.
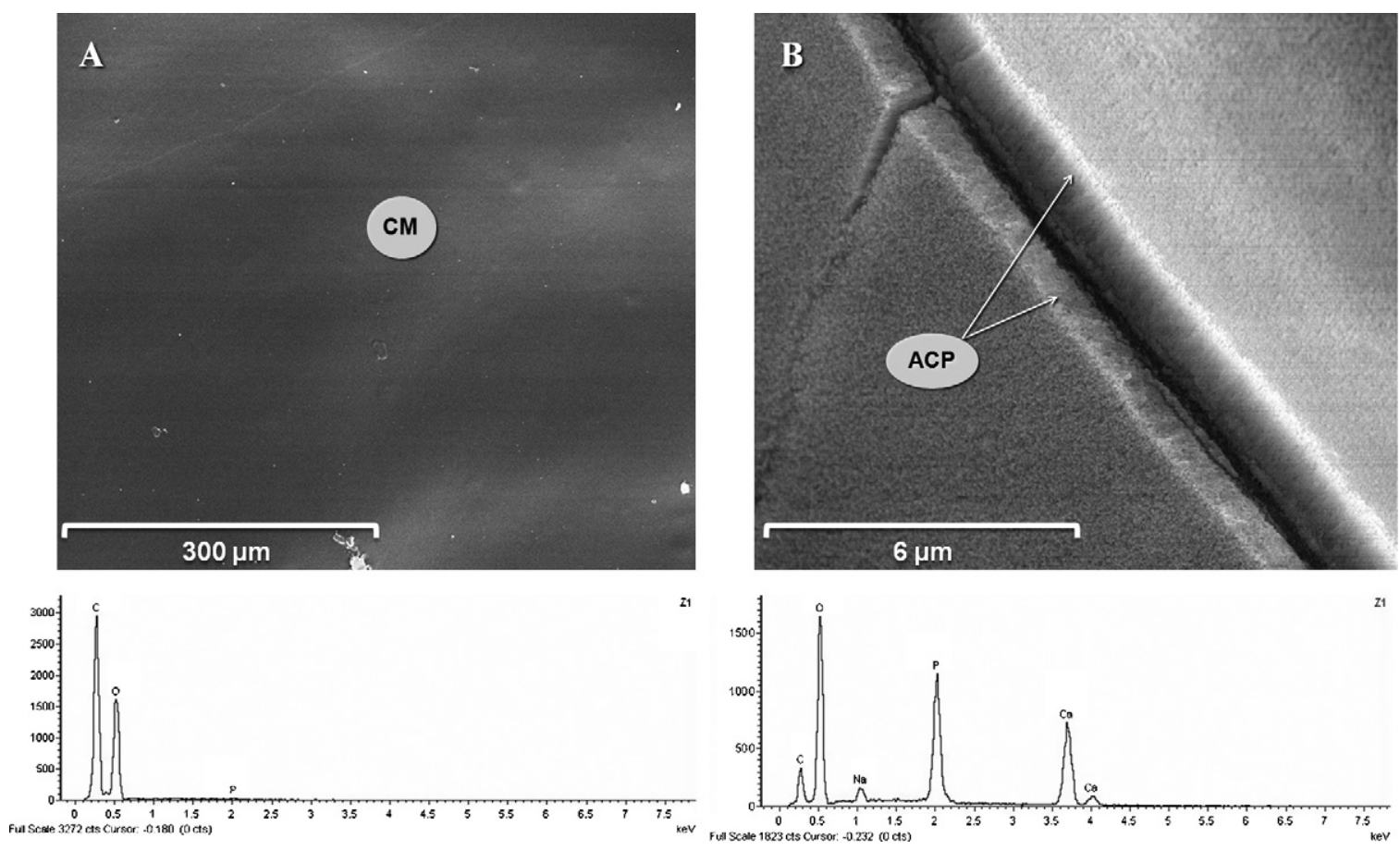

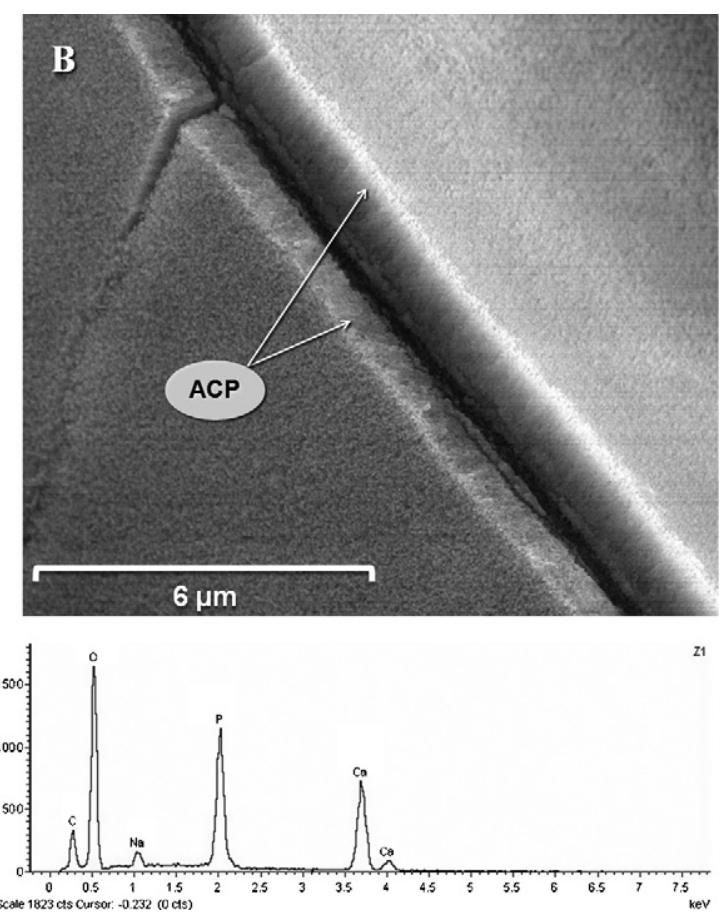

The XRD spectra were performed on a Panalytical Xpert MPD with a $\mathrm{Cu}$ vial.

\subsection{Statistic analyses}

For all experimental situations, the differences in organic and inorganic contents were established between the control values and the mean of $(n=12)$ quantitative measurements of samples collected $6 \mathrm{~h}$ after. These differences were tested for statistical significance by multiple Paired $t$-tests. The significance level for all statistical analyses was set at 0.05 .

\section{Results and discussion}

The first set of experiments with $\mathrm{NaHPO}_{4}$ and $\mathrm{CaCl}_{2}$ bathing only, induced a clear deposit of $\mathrm{CaPO}_{4}$ on the chitosan membrane side directed to the calcium chamber while in the other side the membrane stayed free of any mineral deposit. In fact, the SEM and Energy Dispersive Spectroscopy (EDS) observations showed a calcium phosphate deposit of around $1 \mu \mathrm{m}$ with a smooth surface without any apparent external crystalline structures (Fig. 2). There was also a significant decrease on calcium and phosphate contents from the respective solutions (Table 1). Curiously, these ionic changes were not compensated by equivalent amounts on the opposite sides. So, it is possible to suggest that the main volume of phosphate and calcium ions were precipitated on the membrane under mineral deposits in the calcium chamber side. It is also possible to point out that the chitosan membrane presented a selective permeability relatively to both ions mainly to the phosphate. Since

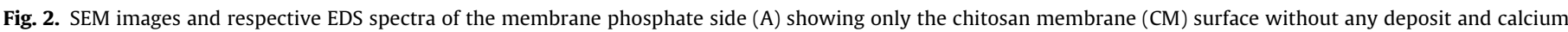
side (B) with a layer of amorphous calcium phosphate (ACP). 
Table 2

Phosphate and calcium variations on the solutions with membranes embedded in haemolymph $(n=12)$.

\begin{tabular}{|c|c|c|c|c|}
\hline & \multicolumn{2}{|l|}{$t=0 \mathrm{~h}$} & \multicolumn{2}{|l|}{$t=6 \mathrm{~h}$} \\
\hline & Phosphate chamber & Calcium chamber & Phosphate chamber & Calcium chamber \\
\hline Phosphate (mmol/L) & 20 & 0 & $11.4 \pm 5.37$ & $0.05 \pm 0.01$ \\
\hline Calcium (mmol/L) & 0 & 20 & $0.07 \pm 0.01$ & $16.65 \pm 0.85$ \\
\hline
\end{tabular}

Table 3

Phosphate and calcium variations on the solutions with membrane embedded in extrapallial $(n=12)$.

\begin{tabular}{|c|c|c|c|c|}
\hline & \multicolumn{2}{|l|}{$t=0 \mathrm{~h}$} & \multicolumn{2}{|l|}{$t=6 \mathrm{~h}$} \\
\hline & Phosphate chamber & Calcium chamber & Phosphate chamber & Calcium chamber \\
\hline Phosphate (mmol/L) & 20 & 0 & $10.86 \pm 5.16$ & $0.06 \pm 0.03$ \\
\hline Calcium $(\mathrm{mmol} / \mathrm{L})$ & 0 & 20 & $0.05 \pm 0.01$ & $17.23 \pm 1.00$ \\
\hline
\end{tabular}

the $\mathrm{PO}_{4}{ }^{3-}$ ion has a higher molecular size than the $\mathrm{Ca}^{2+}$ ion and the chitosan membrane has positively charged pores, it is possible to speculate that this fact induces phosphate ion movements from the phosphate chamber towards the calcium chamber where it precipitates on the membrane under $\mathrm{CaPO}_{4}$.

In the second experimental set with membranes previously impregnated on haemolymph and extrapallial fluid from A. cygnea, and bathed in the chambers by the same inorganic solutions, above mentioned, similar calcium phosphate deposits were observed by SEM in the membrane on the calcium chamber side of the membrane (Fig. 2). A significant decrease on the calcium and phosphate ion content was detected, with haemolymph and extrapallial respectively (Tables 2 and 3 ). However, these ionic variations with impregnated membrane were higher than in the experiments without biological fluids impregnated membranes (first set) suggesting an active role to specific organic molecules in the bivalve fluids.

In the third experimental set where the haemolymph or extrapallial fluids from A. cygnea were added to the calcium chamber, the chitosan membrane also presented on the same side similar calcium phosphate layer features by SEM and EDS (Fig. 2). In this case, specific organic compounds were measured in these fluids at time zero and $6 \mathrm{~h}$ after, showing a significant decline on total protein, Gag and lipid contents (Fig. 3). According to these results it is possible to suggest a direct contribution of these elements in order to form a biomineral layer.
In order to understand the $\mathrm{pH}$ influence on the precipitation process, a fourth experimental set was carried out where calcium and phosphate solutions differed only on $\mathrm{pH}$ values, that were set to $6(\mathrm{HCl}), 7(\mathrm{HCl})$ and $9(\mathrm{NaOH})$. Observations by SEM and EDS demonstrate that, in all these assays, calcium phosphate precipitation occurred only on the calcium chamber side of the membrane. At pH 7 and 9 a coat of amorphous calcium phosphate, similar to the other sets, was formed (Fig. 2), but at $\mathrm{pH} \mathrm{6}$, on this amorphous layer, well defined, calcium phosphate hexagonal crystal formations were observed (Fig. 4B). These results suggest that an alkaline environment induced a rapid precipitation that does not allow an external habit under a crystalline form, while an acidic environment favours a slower precipitation where a more structured form could be constructed.

Although with the same $\mathrm{pH}$ 6, the different acids used to set this $\mathrm{pH}$ value revealed different results. With $\mathrm{pH} 6(\mathrm{HCl})$ (Fig. 4A), single crystal forms were observed in great numbers. On the other hand, when $\mathrm{pH}$ 6(succinic acid) was used, few crystalline forms were constructed (Fig. 4B). Additionally, with citric acid no crystalline formation was observed as in the control set of experiments.

It was observed that haemolymph and extrapallial fluid have in their constitution organic molecules like proteins, GAGs and lipids which contribute to the biomineralization process in the chitosan membranes. When these fluids were introduced in the fifth experimental set maintaining the $\mathrm{pH} 6$, some differences in crystalline forms were denoted comparatively to the others already described.
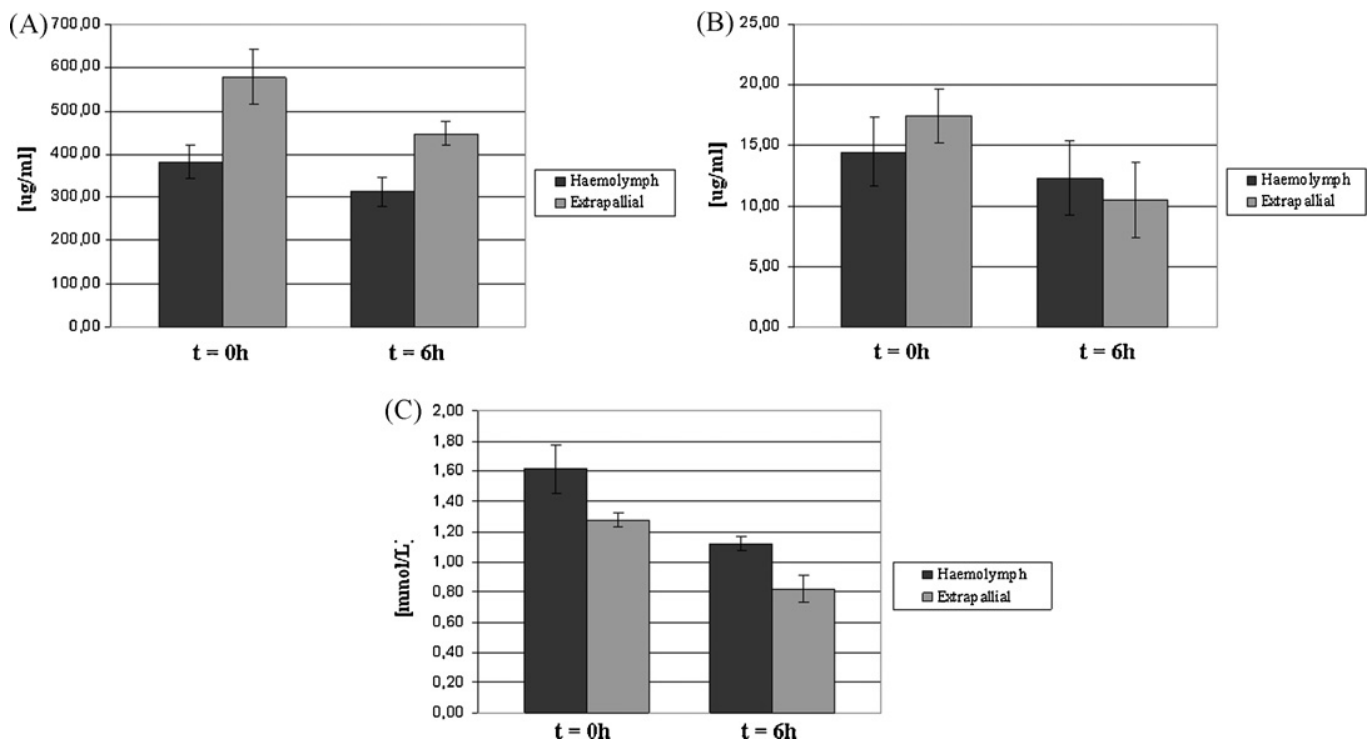

Fig. 3. Variation of total proteins (A), total GAGs (B) and total lipids (C) between times 0 and $6 \mathrm{~h}$ after $(n=12)$. 

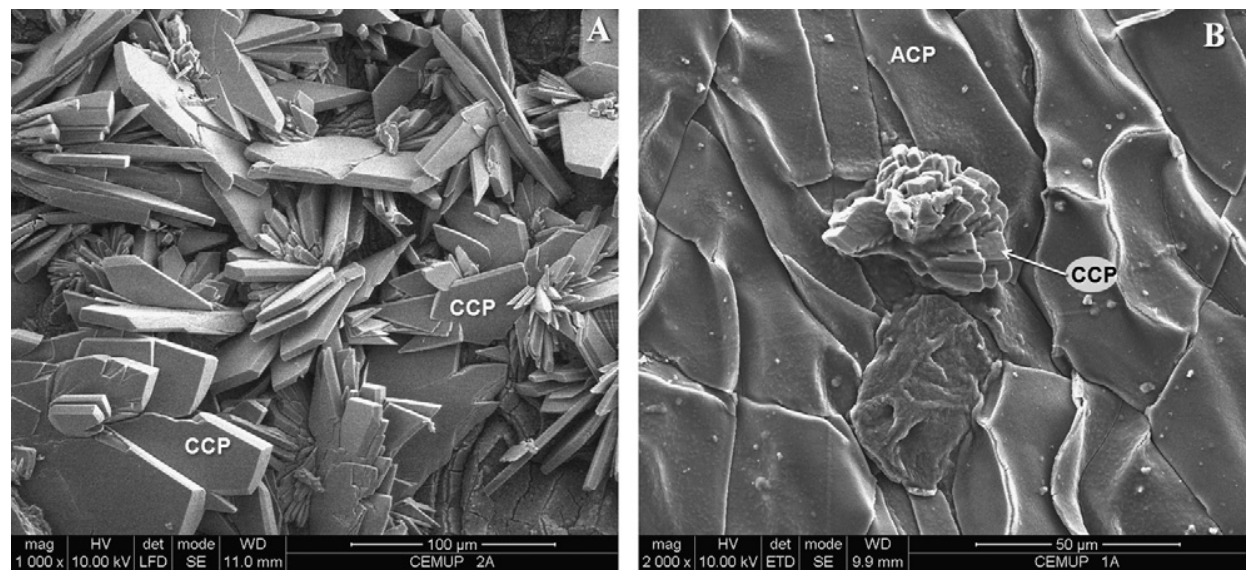

Fig. 4. SEM images of crystalline calcium phosphate (CCP) formed at $\mathrm{pH} 6(\mathrm{HCl})(\mathrm{A})$ and at $\mathrm{pH}$ 6(succinic acid) (B) growing over an amorphous calcium phosphate (ACP) layer.

So, at $\mathrm{pH} 6(\mathrm{HCl})$ and $\mathrm{pH}$ 6(succinic acid) plus both fluids (Fig. 5) the crystals presented an increased size than without fluids (Fig. 4) and were better organized. At pH 6(succinic acid) the crystals have a "rosaceous" form and at $\mathrm{pH} 6(\mathrm{HCl})$ the crystals exhibit a typical hexagonal crystalline formation. At $\mathrm{pH}$ 6(citric acid) with biological fluids the results were very similar to the control, i.e., no crystalline formation was constructed.

In summary, the results suggest that the synthetic solutions with $\mathrm{HCl}$ and succinic acid induced dispersed crystalline structures while the citric solution did not produce any crystals. Moreover, the addition of organic fluids promoted an intense aggregation and an increase of calcium phosphate crystalline structures only when there is a natural tendency to form crystals ( $\mathrm{HCl}$, succinic acid).

So, as in shell construction on A. cygnea, specific molecules of respective biological composites should nucleate and be responsible for the modulation of calcium phosphate polymorphic structures determining the crystalline shape and acting as glue stabilizing crystal structure (Figs. 6 and 7).

\subsection{Nature of mineral layers}

The X-ray analyses of the deposited mineral layers on the chitosan membranes showed precipitation of calcium phosphate as a crystalline structure assigned to hydroxyapatite. Surface area observed by electron microscopy shows major surface of amorphous phases and crystalline phases displaying the hexagonal shapes. The crystals under the hexagonal forms are mainly observed on the $\mathrm{pH} 6.0$ with or without any organic fluids.
The studied materials by both FTIR and XRD techniques confirm an excellent crystallinity of hydroxyapatite. FTIR spectra of the samples $\mathrm{C} 1, \mathrm{C} 2, \mathrm{~S} 1, \mathrm{~S} 3, \mathrm{Ct} 1$ and $\mathrm{Ct} 3$ show a single $v_{3}$ asymmetrical vibration corresponding to tetrahedral molecule of $\mathrm{PO}_{4}{ }^{3-}$ ions at about $1010 \mathrm{~cm}^{-1}$. The narrowness vibration is assigned to the $\mathrm{P}-\mathrm{O}$ stretching band (Td symmetry) Fundamental vibrational frequency $\left(v_{3}\right)$ of $\mathrm{HPO}_{4}{ }^{2-}$ anion is correlated with both vibration planes at $1010 \mathrm{~cm}^{-1}$ and $1070(1080) \mathrm{cm}^{-1}$. The band at $1070 \mathrm{~cm}^{-1}$ occurs as a shoulder at the P-O stretching band (samples C1, C2, C3, $\mathrm{S} 1, \mathrm{~S} 3, \mathrm{Ct} 1, \mathrm{Ct} 2$ and $\mathrm{Ct} 3$ ).

A tetragonal penta-atomic molecule (e.g., $\mathrm{PO}_{4}{ }^{3-}$ ) exhibits four different vibrations (i) the symmetric stretching $\left(v_{1}\right)$, (ii) the symmetric bending $\left(v_{2}\right)$, (iii) the asymmetric stretching $\left(v_{3}\right)$ and (iv) the asymmetric bending $\left(v_{4}\right)$. Thus, the FTIR spectra collected of the samples studied display a typical asymmetric stretching $\left(v_{3}\right)$.

However, the $\mathrm{C}-\mathrm{O}$ vibration planes related to chitosan may be well observed in this wave region when hydroxyapatite is poorly crystallized. In our case, the asymmetric vibration of $\mathrm{PO}_{4}{ }^{3-}$ ions could be also due to vibration planes of chitosan, where the shoulder at $1070 \mathrm{~cm}^{-1}$ could be also assigned to the $\mathrm{C}-\mathrm{O}$ stretching [21].

The $v_{1}$ vibration shifts at about $870 \mathrm{~cm}^{-1}$ (sample C3). However, the band vibration assigned as a shoulder at about $883-890 \mathrm{~cm}^{-1}$ (samples $\mathrm{C} 1, \mathrm{C} 2, \mathrm{~S} 1, \mathrm{~S} 3, \mathrm{Ct} 1, \mathrm{Ct} 2$ and $\mathrm{Ct} 3$ ), should be also related to $\mathrm{C}-\mathrm{O}$ band of chitosan [21].

Sample S2 show a ferric hydroxyphosphate complexation corresponding to a fundamental monodentate asymmetrical vibration $\left(v_{3}\right)$ at $980 \mathrm{~cm}^{-1}, 1051 \mathrm{~cm}^{-1}$ and $1118 \mathrm{~cm}^{-1}$. Probably goethite $[(\mathrm{FeO}(\mathrm{OH})]$ was precipitated later or joined with phosphate.
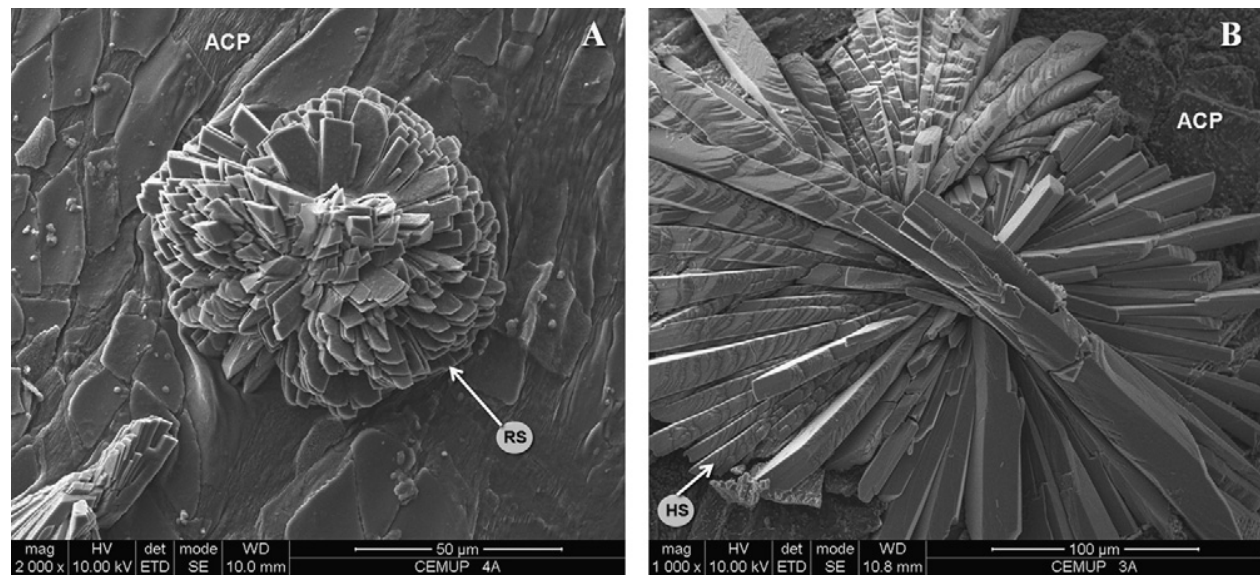

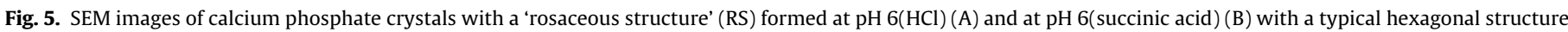
(HS) plus A. cygnea fluid. Both crystals grew over an amorphous calcium phosphate (ACP) layer. 

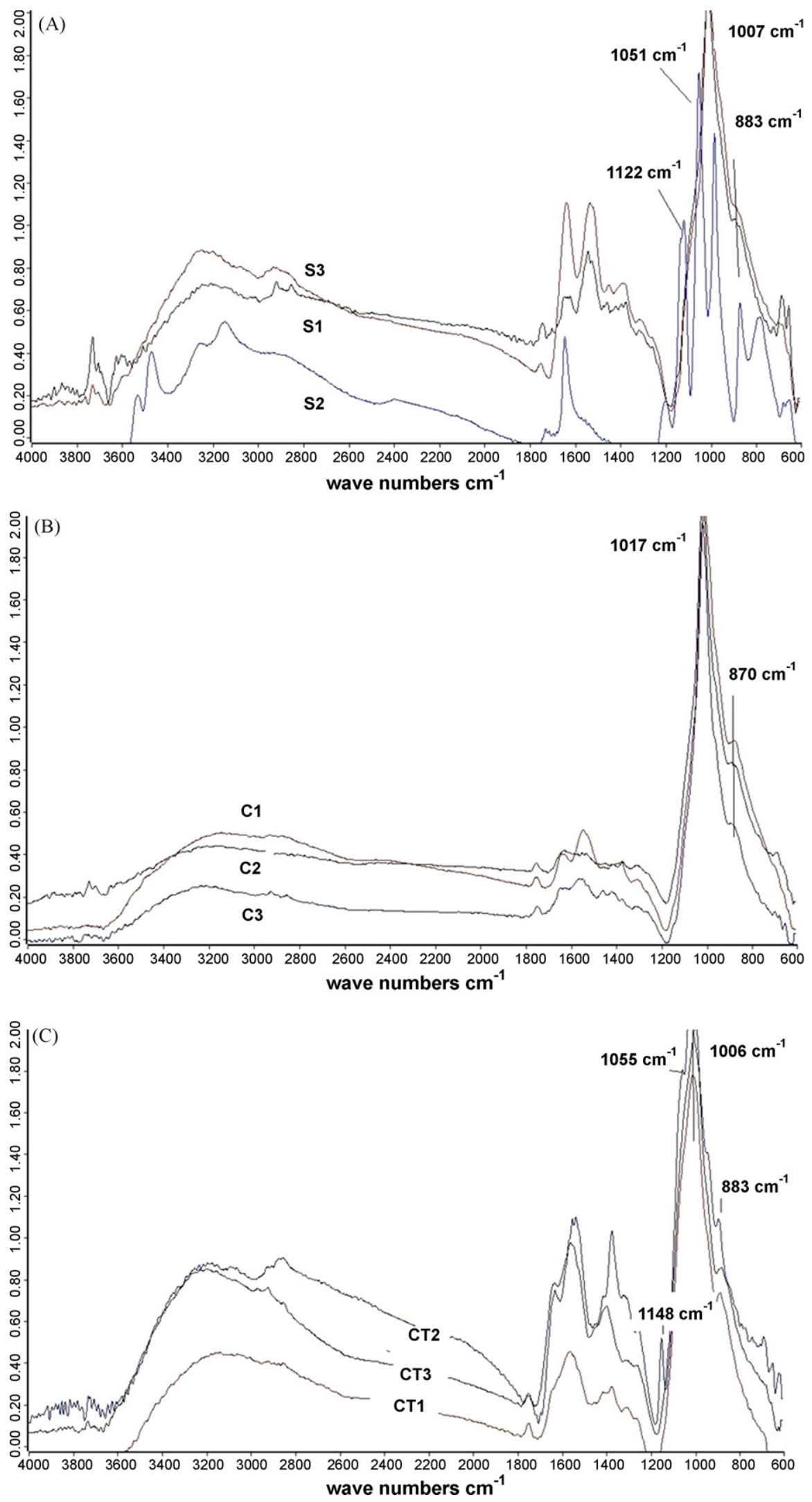

Fig. 6. FTIR spectra of chitosan membrane in the calcium chamber side. (A) $\mathrm{C} 1, \mathrm{C} 2$ and $\mathrm{C} 3$ represent $\mathrm{pH} 6(\mathrm{HCl}), \mathrm{pH} 7(\mathrm{HCl})$ and pH 9(NaOH), respectively. (B) S1, $\mathrm{S} 2$ and $\mathrm{S} 3$ refers to $\mathrm{pH}$ 6(succinic acid), $\mathrm{pH}$ 6(succinic acid/haemolymph) and pH 6(succinic acid/extrapallial), respectively. (C) CT1, CT2 and CT3 refers to pH 6(citric acid), pH 6(citric acid/haemolymph) and pH 6(citric acid/extrapallial) respectively. 


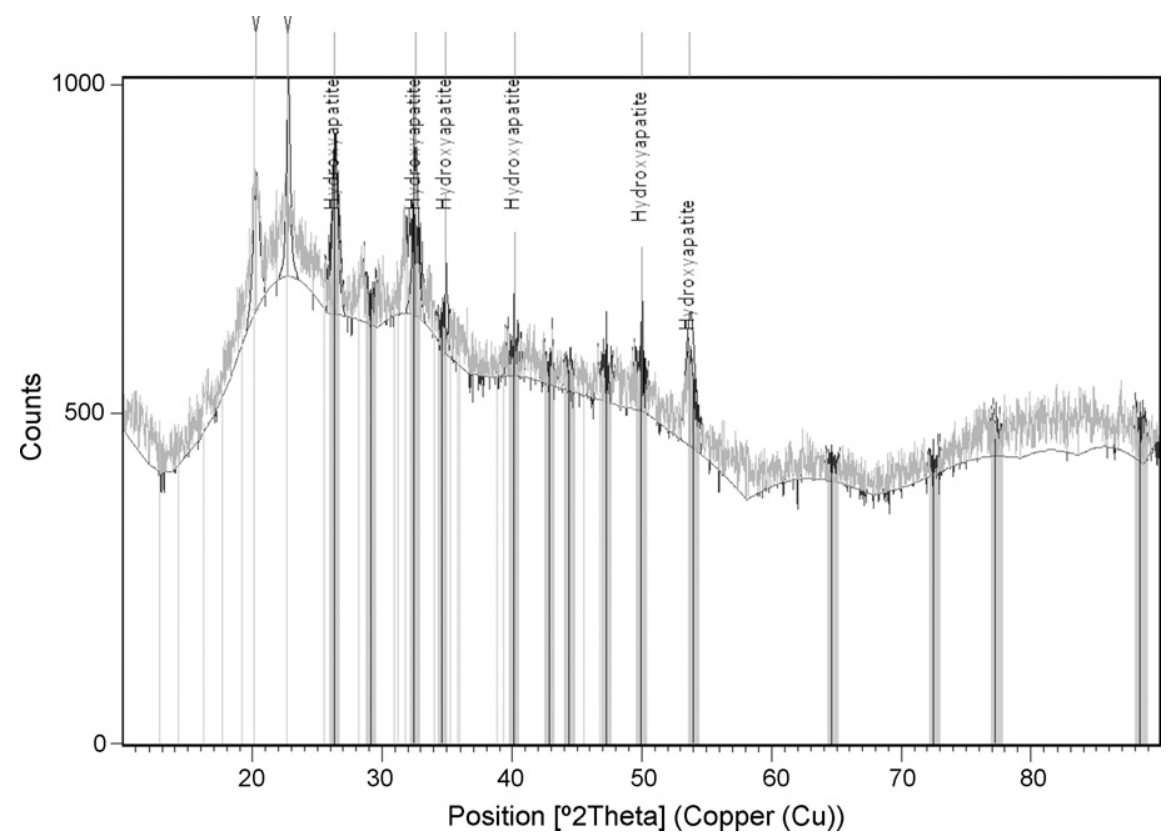

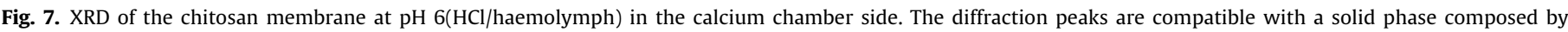
hydroxyapatite. The vertical axis represents X-ray intensity. The horizontal axis records angles in degrees $(2 \theta)$ with time steps of $60 \mathrm{~s}$ between $10^{\circ}$ and $90^{\circ}$.

The $\mathrm{OH}^{-}$-band is well observed at $3500 \mathrm{~cm}^{-1}$ and $3400 \mathrm{~cm}^{-1}$ in the samples studied. However, the $\mathrm{OH}^{-}$-bands at 3500 and $3400 \mathrm{~cm}^{-1}$ are not observed in samples $\mathrm{C} 2, \mathrm{~S} 1, \mathrm{~S} 3, \mathrm{Ct} 1$ and $\mathrm{Ct} 3$ studied, probably due to $\mathrm{Ca}(\mathrm{OH})_{2}$ impurities.

The band at $2900 \mathrm{~cm}^{-1}$ is assigned to $-\mathrm{CH}_{2}$, often used as reference band for chitosan [22]. The band at $1633 \mathrm{~cm}^{-1}$ is assumed to water, indicating the interaction of the amine on the chitosan and phosphates in the solution [23]. Both bands at 1525 and $1379 \mathrm{~cm}^{-1}$ are assumed to $\mathrm{CO}_{3}{ }^{2-}$, being well highlighted in samples $\mathrm{S} 2$ and Ct2.

The vibration planes observed in the FTIR spectra suggest the presence of hydroxyapatite (samples C1, C2, S1, S3, Ct1 and Ct3) and Fe-hydroxyapatite (sample S2 and $\mathrm{Ct} 2$ ). The presence of $\mathrm{Fe}^{2+}$ ion in haemolymph and extrapallial, 16.0 and $15.0 \mu \mathrm{M}$ respectively, can explain the fact to form Fe-hydroxyapatite. However, the selective presence of $\mathrm{Fe}^{2+}$ only in the deposit of haemolymph samples can suggest any specific mechanism of complexation, probably based on particular biomolecules which can induce preferred precipitation on the chitosan membranes.

\section{Conclusions}

Considering the present results it is possible to suggest three distinct and interesting points. One is that the chitosan membrane may function as a selective epithelium where preferred ionic movements and subsequent specific biomineralization occur in only one face of the membrane. This particular behaviour might be due to the charge effects between the ions and the membrane pores.

The second aspect concerns the properties of the mineral deposit obtained in varied conditions. For general situations, it is possible to indicate that the chitosan biomineralized surface is composed by an amorphous mineral layer where intrinsic hydroxiapatite crystals may be formed. Additionally, under specific cases, these crystals may exhibit specific hexagonal forms induced by a low pH 6.

A third point is relative to the organic compounds which seem to have a clear effect by ionotropic and/or epitaxial effects over the hydroxiapatite crystals inducing accentuated hexagonal shapes, or forming a very typical and intense rosaceous shape when influ- enced by the proteins, GAGs and lipids from the haemolymph or extrapallial fluids of $A$. cygnea, mainly under the action of succinic acid.

So, these properties of the chitosan membrane to assume those physical-chemical behaviours, under very particular conditions and processes, may be used in several fields on the development of biological, bioengineering or even medical applications. In fact, these biological fluids with natural biomineralizing components should be also thoroughly researched in this sense, as adequate mineral nucleators and modulators.

\section{Acknowledgements}

The authors were supported by FEDER under project PROTEUSINTERREG III A-SP1.P151/03 and Fundação para a Ciência e Tecnologia (FCT). We would also like to thank António Rocha for the laboratorial expertise.

\section{References}

[1] P. Madhavan, Chitin, Chitosan and Their Novel Applications, Central Institute of Fisheries Technology, Kochi, India, 1992

[2] H. Ehrlich, B. Krajewska, T. Hanke, R. Born, S. Heinemann, C. Knieb, H. Worch, Chitosan membrane as a template for hydroxyapatite crystal growth in a model dual membrane diffusion system, J. Membr. Sci. 273 (2006) 124-128.

[3] W. Paul, C.P. Sharma, Chitosan, a drug carrier for the 21st century: a review, STP Pharm. Sci. 10 (2000) 5-22.

[4] K.M. Wilbur, Shell formation in molluscs, in: M. Florkin, B.T. Scheer (Eds.) Chemical Zoology, vol. 6, Academic Press, New York, 1972, pp. 103-145.

[5] K.M. Wilbur, Recent studies of invertebrate mineralization, in: N. Watabe, K.M. Wilbur (Eds.), The Mechanisms of Mineralization in the Invertebrates and Plants, Univ. of South Carolina Press, Columbia, 1976, pp. 74-108.

[6] K.M. Wilbur, Many minerals, several phyla, and a few considerations, Am. Zool 24 (1984) 839-845.

[7] M.A. Crenshaw, The inorganic composition of molluscan extrapallial fluid, Biol. Bull. 143 (1972) 506-512.

[8] L. Addadi, S. Weiner, Interactions between acidic proteins and crystals: stereochemical requirements in biomineralization, Proc. Natl. Acad. Sci. U.S.A. 82 (1985) 4110-4114.

[9] G. Moura, L. Vilarinho, A.C. Santos, J. Machado, Organic compounds in the extrapallial fluid and haemolymph of Anodonta cygnea (L.) with emphasis on the seasonal biomineralization process, Comp. Biochem. Physiol. Part B 125 (2000) 293-306.

[10] H. Ehrlich, Chitin and collagen as universal and alternative templates in biomineralization, Int. Geol. Rev. 52 (2010) 661-699. 
[11] G. Moura, R. Guedes, J. Machado, Annual compositional and morphological variations in the nacreous layers of the shell of Anodonta cygnea, Malacol. Rev. 33-34 (2001) 106-111.

[12] M. Lopes-Lima, I.R.A. Ribeiro, R.A. Pinto, J. Machado, Isolation, purification and characterization of glycosaminoglycans in the fluids of Anodonta cygnea, Comp. Biochem. Physiol. A 141 (2005) 319-326.

[13] M. Lopes-Lima, R. Bleher, T. Forg, M. Hafner, J. Machado, Studies on a PMCA-like protein in the outer mantle epithelium of Anodonta cygnea: insights on calcium transcellular dynamics, J. Comp. Physiol. B 178 (2008) 17-25.

[14] M. Lopes-Lima, A. Lopes, P. Casaca, I. Nogueira, A. Checa, J. Machado, Seasona variations of $\mathrm{pH}, \mathrm{pCO}_{2}, \mathrm{pO}_{2}, \mathrm{HCO}_{3}{ }^{-}$and $\mathrm{Ca}^{2+}$ in the haemolymph: implications on the calcification physiology in Anodonta cygnea, J. Comp. Physiol. B 179 (2009) 279-286.

[15] J.F. Mano, Viscoelastic properties of chitosan with different hydration degrees as studied by dynamic mechanical analysis, Macromol. Biosci. 8 (2008) 69-76.

[16] G. Moura, M.J. Almeida, M.J. Machado, L. Vilarinho, J. Machado, The action of environmental acidosis on the calcification process of Anodonta cygnea (L.) in: I. Kobayashi, H. Ozawa (Eds.), Biomineralization (BIOM2001): Formation, Diversity, Evolution and Application, Proceedings of the 8th International Sym- posium on Biomineralizations, Tokai Univ, Press, Kanagawa, 2003, pp. 178182 .

[17] M.M. Bradford, A rapid and sensitive method for quantitation of microgram quantities of protein utilizing the principle of protein-dye binding, Anal. Biochem. 72 (1976) 248-254.

[18] E.W. Gold, A simple spectrophotometric method for estimating glycosaminoglycan concentrations, Anal. Biochem. 99 (1979) 183-188.

[19] E.W. Gold, The quantitative spectrophotometric estimation of total sulphated glycosaminoglycan levels, Biochim. Biophys. Acta 673 (1981) 408-415.

[20] E.G. Bligh, W.J. Dyer, A rapid method of total lipid extraction and purification, Can. J. Biochem. Physiol. 37 (1959) 911-917.

[21] I. Manjubala, S. Scheler, J. Bössert, K.D. Jandt, Mineralisation of chitosan scaffolds with nano-apatite formation by double diffusion technique, Acta Biomater. 2 (1) (2006) 75-84.

[22] J. Brugnerotto, J. Lizardi, F.M. Goycoolea, W. Argüelles-Monal, J. Desbrières, M. Rinaudo, An infrared investigation in relation with chitin and chitosan characterization, Polymer 42 (2001) 3569-3580.

[23] Z.K. Jonathan, M.H. Samuel, A.M.C. Katherine, Improved mechanical properties of chitosan fibres, J. Appl. Polym. Sci. 72 (1999) 1721-1732. 